\title{
Vasoconstrictors in combination with proton pump inhibitors as an initial treatment of acute upper gastrointestinal bleeding in liver cirrhosis: is it evidence based?
}

\author{
Fan Gao ${ }^{1,2}$, Nahum Méndez-Sánchez ${ }^{3}$, Xingshun $\mathbf{Q i}^{2}$ \\ ${ }^{1}$ Medical Department, No. 202 Hospital of Chinese PLA, Shenyang 110003, China; ${ }^{2}$ Liver Cirrhosis Group, Department of Gastroenterology, \\ General Hospital of Shenyang Military Area, Shenyang 110840, China; ${ }^{3}$ Liver Research Unit Medica Sur Clinic \& Foundation, Mexico City, Mexico \\ Correspondence to: Dr. Xingshun Qi, MD. Department of Gastroenterology, General Hospital of Shenyang Military Area, Shenyang 110840, China. \\ Email: xingshunqi@126.com.
}

Submitted Jul 20, 2018. Accepted for publication Aug 07, 2018.

doi: 10.21037/atm.2018.08.07

View this article at: http://dx.doi.org/10.21037/atm.2018.08.07

Recently, an interesting Spanish multicenter cohort study by Ardevol et al. (1) found that the risk of further bleeding and 45-day mortality were statistically similar in cirrhotic patients with acute upper gastrointestinal bleeding (AUGIB) from varices and peptic ulcer. Notably, the researchers employed the same first-line treatment strategy before endoscopy regardless of source of upper gastrointestinal bleeding, which included vasoconstrictors, proton pump inhibitors (PPIs), and prophylactic antibiotics. This seems to be different from the current recommendations from the mainstream consensus and guidelines (Figure 1).

The Asia-Pacific Working Group consensus and American College of Gastroenterology practice guideline $(2,3)$ recommend that high-dose PPIs are the core treatment options for acute peptic ulcer bleeding. However, there is no recommendation regarding the use of vasoconstrictors for acute peptic ulcer bleeding, in spite of its potential benefit in scattered case reports (4). On the other hand, the Baveno VI consensus (5), 2016 American Association for the Study of Liver Diseases (AASLD) practice guidance (6), and updated UK guideline (7) recommend that vasoconstrictors are the first-line choice of therapy for acute variceal bleeding (AVB) in liver cirrhosis. However, there is no recommendation from the Baveno VI consensus and 2016 AASLD practice guidance regarding the use of PPIs for AVB $(5,6)$. What deserves to be mentioned the most is that the updated UK guideline does not support the use of PPIs for AVB because it may increase the risk of bacterial infection in liver cirrhosis (7). Evidence also suggested that the use of PPIs might increase the risk of infection, such as nosocomial pneumonia (8), Clostridium difficile infection (9), and spontaneous bacterial peritonitis, and hepatic encephalopathy in liver cirrhosis (10-12).

Although it should be recognized that the mortality due to uncontrolled bleeding was very low in the study ( $2 \%$ in peptic ulcer bleeding and $3 \%$ in AVB), we should be cautious that such a stereotyped treatment strategy is not based on the current evidence. Additionally, we should acknowledge that the source of bleeding is always obscure at the patients' admissions. Therefore, further well-designed researches should be necessary to explore the efficacy and safety of vasoconstrictors combined with PPIs for AUGIB in liver cirrhosis. 


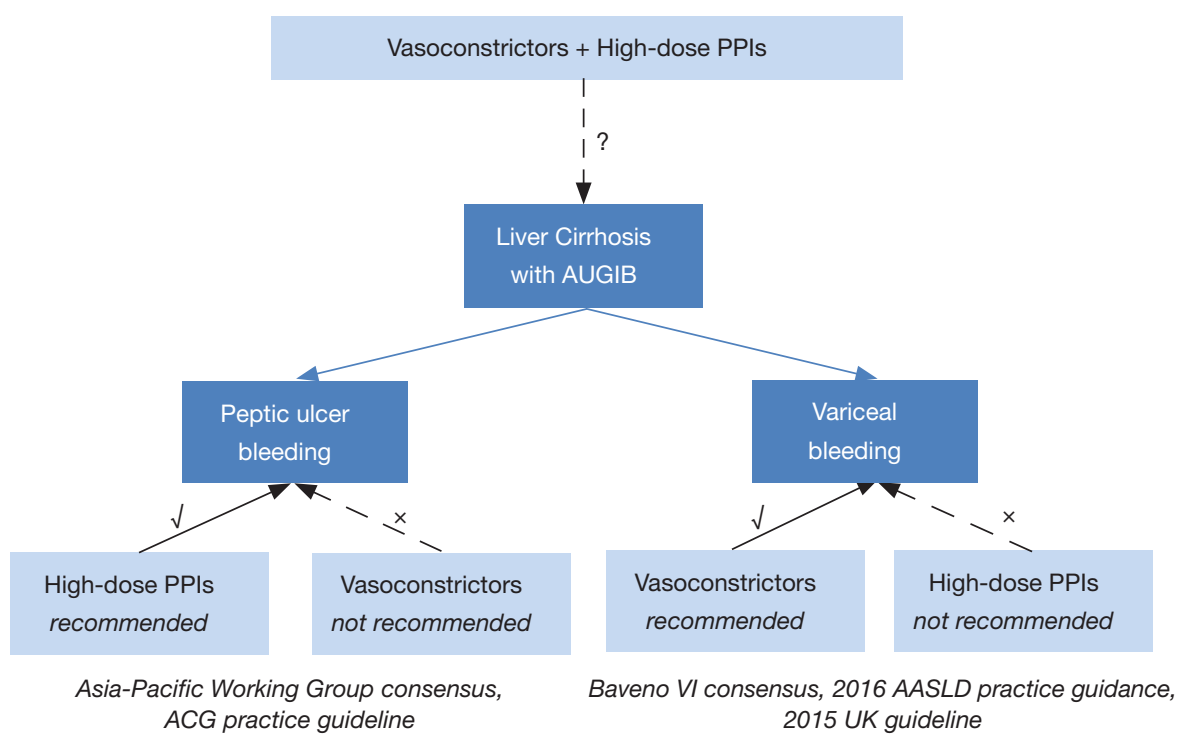

Figure 1 A schematic representation of our comments to the paper by Ardevol et al. (Hepatology 2018;67:1458-71).

\section{Acknowledgements}

None.

\section{Footnote}

Conflicts of Interest: The authors have no conflicts of interest to declare.

\section{References}

1. Ardevol A, Ibanez-Sanz G, Profitos J, et al. Survival of patients with cirrhosis and acute peptic ulcer bleeding compared with variceal bleeding using current first-line therapies. Hepatology 2018;67:1458-71.

2. Laine L, Jensen DM. Management of patients with ulcer bleeding. Am J Gastroenterol 2012;107:345-60; quiz 61.

3. Sung JJ, Chan FK, Chen M, et al. Asia-Pacific Working Group consensus on non-variceal upper gastrointestinal bleeding. Gut 2011;60:1170-7.

4. Qi X, Li H, Shao X, et al. Should Vasoconstrictors be Considered in a Cirrhotic Patient with Acute Non-variceal Upper Gastrointestinal Bleeding? J Transl Int Med 2017;5:240-4.
5. de Franchis R. Expanding consensus in portal hypertension: Report of the Baveno VI Consensus Workshop: Stratifying risk and individualizing care for portal hypertension. J Hepatol 2015;63:743-52.

6. Garcia-Tsao G, Abraldes JG, Berzigotti A, et al. Portal hypertensive bleeding in cirrhosis: Risk stratification, diagnosis, and management: 2016 practice guidance by the American Association for the study of liver diseases. Hepatology 2017;65:310-35.

7. Tripathi D, Stanley AJ, Hayes PC, et al. UK guidelines on the management of variceal haemorrhage in cirrhotic patients. Gut 2015;64:1680-704.

8. Herzig SJ, Howell MD, Ngo LH, et al. Acid-suppressive medication use and the risk for hospital-acquired pneumonia. JAMA 2009;301:2120-8.

9. Linsky A, Gupta K, Lawler EV, et al. Proton pump inhibitors and risk for recurrent Clostridium difficile infection. Arch Intern Med 2010;170:772-8.

10. Dam G, Vilstrup H, Watson H, et al. Proton pump inhibitors as a risk factor for hepatic encephalopathy and spontaneous bacterial peritonitis in patients with cirrhosis with ascites. Hepatology 2016;64:1265-72.

11. Zhu J, Yu H, Mancuso A, et al. Proton pump inhibitors in 
liver cirrhosis: a review of benefits and harms. AME Med J 2017;2:36.

12. Zhu J, Qi X, Yu H, et al. Association of proton pump

Cite this article as: Gao F, Méndez-Sánchez N, Qi X. Vasoconstrictors in combination with proton pump inhibitors as an initial treatment of acute upper gastrointestinal bleeding in liver cirrhosis: is it evidence based? Ann Transl Med 2018;6(16):327. doi: 10.21037/atm.2018.08.07 inhibitors with the risk of hepatic encephalopathy during hospitalization for liver cirrhosis. United European Gastroenterol J 2018. [Epub ahead of print]. 